\title{
An Optimal e-working Environment: Online Survey Results
}

\author{
Michal Beno \\ Institute of Technology and Business in Ceske Budejovice \\ Email: beno@mail.vstecb.cz \\ Czechia \\ Jozef Hvorecky \\ Institute of Technology and Business in Ceske Budejovice \\ Email: jozef@hvorecky.com \\ Czechia \\ Dagmar Caganova \\ Institute of Industrial Engineering and Management \\ Faculty of Materials Science and Technology \\ Email: dagmar.caganova@stuba.sk \\ Slovakia
}

\section{ABSTRACT}

E-working undergoes a facelift. Its present extent and format are extending to (re)define the future of workplaces. The consequences of the sudden arrival COVID-19 pandemic are not fully understood yet, because a radical evolution of work is still running. Over the past few months, nearly every organization seems to have implemented its e-working practices. Some of them contradict each other, which may lead to confusion and disharmony. It opens the question of creating and developing optimal e-worker-friendly environments. On 11 May 2020, the authors of the paper launched an online survey to gather important data to determine how workers of different subsidiaries of an international organization were coping with this sudden change. In 154 responses, they shared their feelings on the recent workplace challenges as well as future perspectives. In the survey, the respondents and their workplaces confirmed their quick adaption to e-working. More than half of them feel more productive at home than in the office. They indicate their preference for a smart casual dress code. More than one-third of respondents would like to extend working from home to a longer period (1-2 years). They see their subsidiaries not having developed a return-to-work strategy as a problem. Another big issue is the blurred line between personal and work life. Data provide strong evidence of the benefits of e-working and constitute a set of recommendations for this type of work in the future. The conclusions have been generalized to a model that can guide organizations in managing their e-working balanced and positively expanding.

\section{Keywords: e-working, workplace culture, future perspectives, Out-of-Office model.}

\section{Introduction}

A global pandemic of an unprecedented magnitude is looming. Its result may lead to probably the biggest economic crisis in the post-war period. At the same time, as Ed Conway (2020) says: "COVID-19 can trigger a new industrial revolution".

The authors of the paper support his statement, that "it could be the shock we need to harness new technology and new ways of working". Innovative organization of work through teleworking, if the job allows for working remotely, has been adopted by organizations in response to the COVID19 threat (Belzenegui-Eraso and Erro-Carcés, 2020).

A 2019 report shows that just $62 \%$ of the surveyed people have worked remotely with some frequency (OWLLabs, 2019). Generally, across the EU, five out of ten people between 15 and 64 years of age have been working regularly from home consistently over the past 10 years. In certain parts of Eastern Europe, however, rates are much lower than this average. The lowest rates found were in Romania and Bulgaria (Eurostat, 2020). During the pandemic and into the present, the idea of e-working seems to no longer be a choice; it is a matter of necessity. As a result, e-working has opened up wider questions around the nature of work, including the necessity of workspaces.

Simply, e-working means more efficient utilization of ICT (Information and Communication Technology) rather than non-commuting to work (Beňo and Ferenčiková, 2019). In the past, challenging problems, insufficient end-user infrastructure, and unknown risks faced by employers and employees made eworking difficult. Now, the situation has changed. E-working 


\section{CCenter for Promoting Education and Research (CPER) USA}

WWW.cpernet.org

or teleworking is the modern way of organizing work, whichas the COVID-19 pandemic has shown us-became a standard. Telework has suddenly experienced a rebound, as a result of the measures to protect citizens from coronavirus disease (Belzenegui-Eraso and Erro-Carcés, 2020).

Both employers and employees can benefit from it, especially in terms of flexibility, productivity, and costs. Companies and enterprises are increasingly required to offer adequate forms of work and cooperation, and employees are supposed to respond by their flexibly to new challenges. As stated by Raišiené et al. (2020) the virtual way of working is becoming increasingly popular due to its potential for cost savings; it is also a way for an organization to be more agile and adapt to crises such as global pandemics.

To map the situation, an online survey was drawn up to provide a more detailed view and to examine and analyze the opinion of a group of employees of a global company. The survey's questions addressed the issues and aspects of their activities during the COVID-19 period. The themes included dress code, distractions, social-distance tolerance, productivity, and future outlook.

The results show that the coronavirus has had a substantial impact on the workplace and the culture of work changing them on a big scale: from the mass introduction of eworking (to reach higher productivity) to the importance of online social interaction and company culture (keeping or changing working habits, the style of meetings and events). Policies will need to be adapted to the current and postCOVID situation, discussing all the ways e-work might be beneficial.

The first part provides an account of the e-working concept and workplace culture. In the next paragraphs, the methodology is explained used in our research. The third part presents results. The fourth part gives a brief overview of the future of e-working. Six part closes with a discussion, next section presents limitations and the last section comes to our conclusions.

\section{Conceptual framework}

\subsection{E-working}

While the COVID-19 pandemic triggered a massive move away from the traditional workplace, the evolution of eworking had begun long before that. It is not a new concept. Its history is tightly interwoven with the history of information transfer and technology development.

Managers exploited work and communication from a distance for thousands of years, e.g. the relationship between the Pope and the Byzantine Emperor. So-called papal agents (Latin: papal apocrisarius) were permanent residents of Constantinople (Bischoff and Lapidge, 1994; eDiplomat, 2020). History illustrates how the physical spaces for work respond to cultural, technological, and social forces, e.g. Botticelli's St Augustine in his Cell (Mastromattei, 2017), the painter Carpaccio's view shows St Augustine in His Study from 1503
(Berto, 2016). Before the era of industrialization, working from home was the standard way of life for craftsmen and farmers. Rybczynski (1987) points to the 17th Century as a turning point. The industrialization era dramatically changed workplace models and arrangements and centralized them in specific locations (Beno, 2018). Jack Nilles is considered to be the father of e-working (Beno, 2018b), with ICT playing the essential role today. Due to the COVID-19 pandemic, millions of individuals around the world now work remotely.

The classic definition of teleworking is outdated (Beno, 2018a). There is no universally accepted definition of e-work. Today institutions, academics, politicians, and humankind use adjectives or descriptions such as informative, electronic, digital, tele-, virtual, cyber, flexible, global, nomadic, networked, or simply e-. In a stepwise manner, the term "e-working" replaces a range of different terms such as teleworking, telecommuting, networking, digital nomad, Flexi space to describe how ICT makes information-processing work be carried out at a distance. A similar development leads to considering "e-worker" as a term identifying a teleworker (part-time at home and part-time in the office) or mobile eworker (on the move, outside the home or office, using modern ICT).

E-working is a method of working using ICT in which the work is not bound to any particular location. Traditionally this has been understood as working remotely from the office, usually from home, whether full-time or for a period during the working week (WDC, 2017). E-working is where employees work at home on a full-time/part-time, hybrid basis, or at a different place or virtually. This kind of work involves logging into a work computer remotely (using a virtual private network e.g. Cisco, Barracuda, etc.), sending and receiving email, data, files remotely and developing ideas, products, and services, learning remotely, and other remote business activities. To conclude e-working is a practical approach to accomplish business objectives. This kind of work allows organizations in the private and public sector to operate remotely, employees are absent from their physical workspaces.

\subsection{Workplace culture}

Culture affects every aspect of the work we do. All workplaces have their specific culture that shapes how things are done, how people interact and engage with others, and what is appropriate and acceptable behavior. A positive workplace culture produces adequately-acting employees and creates a pleasant working environment with better outcomes. A poor workplace culture, on the other hand, negatively impacts all participants.

Culture is the tacit social order of an organization (Groysberg et al., 2018). Bodley (1994) explained various definitions of culture from topical, historical, behavioral, normative, mental, functional, structural, to a symbolic point of view. By workplace culture, we understand an environment created for employees. A workplace culture joins the shared 


\section{CCenter for Promoting Education and Research (CPER) USA}

WWW.cpernet.org

values, belief systems, attitudes, and set of assumptions that people in a workplace share (Agarwal, 2018).

Workplace culture is fundamental to an organization as it affects all the ways we think and acts about our work; $82 \%$ of employees consider the culture of an organization to be an important factor when deciding whether to work for an organization (Maxis-gbn, n.d.). Building a positive workplace culture is important for attracting and retaining skilled staff. In "The War of Talent", Michaels et al. (2001) argue that companies have to navigate an increasingly competitive landscape for recruiting and retaining talented employees. Demographic shifts and increasing demand for highly skilled knowledge workers are responsible for the predicted talent shortage. In response to the call to win The War for Talent, the talent management industry has gained momentum and grown in popularity (Michaels et al., 2001).

Thanks to modern technology, ICT has caused a massive shift in work and the workplace. E-working is becoming popular, and nowadays, even a must. Generally, an e-working culture needs excellent communication and the development of positive company culture. In cubicles, culture can evolve through team activities, collaboration, and other shared experiences. An e-working culture requires a rethink of all processes from hiring, onboarding, career, collaboration, trust, safety, and management. It is worth mentioning that changing culture requires the introduction of not only the communication and collaboration infrastructure but also subtler details, such as a room for informal social communication (Dávideková and Hvorecký, 2016).

\section{Methodology}

The usage of the Internet for social science research is becoming increasingly common (Fox et al., 2003). The simplest strategies exploit publicly available tools such as email. The use of e-mail as an alternative not only speeds up communication, it also provides extensive opportunities for data exchange worldwide. During the time of a pandemic, the importance of this exchange grew substantially. The authors of the paper agree with Simsek (1999), that e-mail is not only cheap and fast; its asynchronous nature can lead to a better quality of responses. He adds: "Because e-mail obliterates time and zone constraints, surveying with e-mail can prove to be very beneficial when the sample is scattered and mobile."

The authors of the paper conducted a three-step research investigation to study this topic. The first step was the review of the literature concerning e-working and workplace culture. Secondly, the authors launched an online survey on 11 May 2020 to collect important data on how workers in an international organization were coping, with a randomlyselected sample of 154 workers from different countries worldwide. Thirdly, the future of e-working based on the survey's results was outlined.

The email questionnaire form contained several types of questions (in English) for respondents to answer. The following variables were used: dress code, distractions, socialdistance tolerance, productivity, and future outlook. The study was conducted regardless of gender, however, both genders participated in our research. The participants came from all regions around the world, from towns and cities, from suburbs and the countryside. Although the majority (81\%) described themselves as middle class, nearly half were born into working-class families. They had a wide variety of jobs and careers. The 2020 sample was global (European Union represents more than half the sample, participation from North and South America, Asia, Australia, and Africa participated among the survey). Respondents' ages ranged from 20 to 55 . The sample was a heterogeneous group of professionals working in several areas, including the following: customer services, accounting, electronic data processing, research and development, marketing, and logistics. Responses to the questionnaires were anonymous.

There is a reliability risk regarding e-mail questionnaires. It is more difficult to guarantee their anonymity. The respondents might be afraid of getting their provided information misused. To assure them it does not happen, the authors of the paper proceeded in the following way. First, the secret character of their responses was emphasized in the questionnaire invitation. It also contained the description of the mechanism which was then executed. We used a trusted software that did not allow linking identifiers with their responses. Their ID and responses were stored in different files. Then, the authors made certain that all IP addresses, e-mail data, and other person-related data were not archived.

\section{Results}

The COVID-19 pandemic has led to the closure of many businesses and restricted a large number of people to resort to working from home or other secluded environments. Organizations were confronted with an array of issues for keeping employees, clients, and stakeholders safe after their return and protecting their future business and workplace outlooks. The authors of the paper have been interested in collecting important data on how employees were coping with their specific, unexpected conditions during the pandemic. Based on their responses, the authors have disclosed several key issues their employers should address in the future. Most respondents report a more positive view of e-working than before COVID-19 (62\% positive opinion about e-working compared to $33 \%$ before pandemic).

\subsection{Dress code}

According to Kim Zoller (Icpas, 2017) "55 percent of a person's perception of you is based on how you look." The first impression is always a lasting impression. A recent study by Mentimeter found that $46 \%$ of people spend more time on their appearance before a video meeting, and $44 \%$ said they choose to wear different clothes when they make video calls (Ronander, 2020). 


\section{(C) Center for Promoting Education and Research (CPER) USA}

WWW.cpernet.org

The way a person wears their clothes should reflect space to express themselves through clothing, encouraging their personality and the nature of their work: where, when, their uniqueness in the process. This also confirms the results and how it gets done (Beno, 2020a; Randstad, 2019). This has of the authors, as shown in Table 1, that $65.58 \%$ of changed dramatically over the years. Many of those changes respondents wear smart casual dress, compared to $34.42 \%$ who have ultimately contributed to a less formal workplace choose business up top, party down below. (Randstad, 2019). Some companies today give employees the

\section{Table 1. How to dress for success while working from home, $n=154$.}

\begin{tabular}{lll}
\hline & n & \% \\
\hline Wearing smart casual dress & 101 & 65.58 \\
$\begin{array}{l}\text { Business up top, down } \\
\text { below }\end{array}$ & 53 & 34.42 \\
\hline
\end{tabular}

It is important to empower employees to dress for their day and work, as well as show their personality, but it is still important for employers to set some clear guidelines to ensure that everyone feels comfortable (Randstad, 2019). Based on the acquired data, subsidiaries prefer authenticity, creativity, and individuality. Their style of clothing impacts the way they perceive themselves, and this can translate into how productive they become. The concept of "smart casual" which elevates casual clothing into a more refined look might be the best choice for remote workers who want to stay comfortable, yet appropriately dressed for unexpected business calls.

\subsection{Distractors}

The more we become distracted, the harder it becomes to stay productive. It takes an average of 25 minutes (23 minutes and 15 seconds, to be specific) to return to the original task after an interruption, according to Mark et al. (2008). According to Carleton University researchers, people now spend one-third of their time in an office and half of the time they work at home reading and answering emails. Moreover, 30 percent of that time, the emails are neither urgent nor important (Duxbury and Lanctot, 2017). Employees' workdays might be getting longer as a result of certain distractions.

Organizations regularly roll out modern technologies and tools intended to help employees to do their jobs more efficiently, collaborate more directly, and boost their productivity. Yet, all these cause distractions, too. To elaborate on this, the authors of the paper were interested in learning about the biggest distraction during the pandemic working hours. Based on the survey, blurred lines between personal and work life are an issue. As displayed in Table 2, most survey respondents are distracted by family members or children $(29.22 \%), 22.73 \%$ by reading social media, $21.73 \%$ by reading or checking the news, $10.39 \%$ by private phone calls, $9.09 \%$ by housekeeping, $3.89 \%$ by pet sitting, and $3.25 \%$ by playing games.

Table 2. What is your biggest distraction when working from home? $n=154$.

\begin{tabular}{lll}
\hline & n & \% \\
\hline Family members or children & 45 & 29.22 \\
Reading social media & 35 & 22.73 \\
Reading, checking news & 33 & 21.73 \\
Private phone calls & 16 & 10.39 \\
Housekeeping & 14 & 9.09 \\
Pet sitting & 6 & 3.89 \\
Playing games & 5 & 3.25 \\
\hline
\end{tabular}

\subsection{Social-distance tolerance}

Social distance as a term coined by Robert Park addresses the question to "reduce to something like measurable terms the grades and degrees of understanding and intimacy which characterize personal and social relations generally" (Park, 1924). Social distancing is here to stay, and it is going to change our lives (Kucharski, 2017). Harvard scientists guess that we will have to keep the COVID-respecting social distance at least until 2022 when the massive antivirus vaccination is expected (Wood, 2020).

Human beings are social creatures, and social distancing comes easier to some than to others. With all the 
regulations, precautions, and health and safety concerns home (see Table 3). Only $29.22 \%$ of them would be ready to resulting from the pandemic, many people are hesitant to come go back to their regular schedule immediately, $42.21 \%$ prefer back to their offices, use public transport and go back to the to extend working from home for at least 1-2 years, and way things were done before COVID-19. Based on the survey, $28.57 \%$ prefer to do hybrid e-working (partly at home and on average, workers can tolerate two months of working from partly in the office).

Table 3. Return to work, or working at home, $n=154$.

\begin{tabular}{lcc}
\hline & n & \% \\
\hline Get back to office & 45 & 29.22 \\
Extend working from home (1-2 years) & 65 & 42.21 \\
Hybrid e-working $^{1}$ & 44 & 28.57
\end{tabular}

According to the results, the authors believe that a 4- occupations and specific tasks are undertaken. Compared to eday workweek could be the way of the future for social working, the productivity of service jobs requiring physical distancing. These results show that most workers and workplaces have swiftly adapted to e-working. Employees who are currently e-working some amount prefer to work from home 2 days more per week (unweighted average) than they did before COVID-19. Continuing only those who were supported by their employer with continued e-working, represents also a reduction of round-trip commutes per week across the world.

\subsection{Productivity}

Some of the studies reveal the impact on productivity for specific professions (Dutscher, 2012; Bloom et al., 2015; Battiston et al., 2017). These studies suggest that productivity contact with customers such as physicians, nurses, hairdressers, plumbers, caregivers, and waitresses falls prohibitively. Therefore, the current increase in e-working is limited to several categories of white-collar workers (Morikawa, 2020). The surveyed organization belongs among the luckier ones. Being aware of its good luck, it strongly urged its employees to work from home.

Across the survey population of 154 workers, $51.30 \%$ of respondents agreed they were more productive when working from home (see Table 4). Interestingly, $35.71 \%$ felt no difference in productivity between the home and the office, and one-seventh felt less productive while at home. This is from e-working depends on the characteristics of the important evidence for organizations for the future.

Table 4. Are you more or less productive when working from home? $n=154$.

\begin{tabular}{lcc}
\hline & n & \% \\
\hline More productive & 79 & 51.30 \\
Same productivity & 55 & 35.71 \\
\hline
\end{tabular}

While a variety of factors contribute to this heightened sense of e-working productivity, one of the most compelling is the amount of time that workers invest in their workday: $75 \%$ of respondents reported more working hours when working from home. Based on this data, workers spend two additional hours per day working when at home. The e-workers who felt more productive at home reported working four additional hours per day. Their productivity also benefits from time savings related to daily commuting and small-time losses consumed by gossip, noise, and disliked colleagues in cubicles (Beno, 2018b). Considering these results, the authors of the paper conjecture that the productivity of e-working can be higher than productivity in the cubicles. In this research, the positive increase is primarily the result of the respondents'
' A mixture of home and cubicle working, working in hybrid model combining remote and in-person work. personal feelings, and therefore, can be subjective.

\subsection{Future outlook}

No industry or sector has been left unaffected by the outbreak of COVID-19. Many people have had to make significant changes to their lives, including the way they work. Employers cannot force their employees to return to work if it is unsafe. The ILO (2020) has developed a guide containing recommendations for health and safety practices and approaches to COVID-19 prevention.

There seems to be a growing understanding that bringing people together in one place has value, but mobility, social distance, and e-working is now a way of survive. According to the results of the authors' investigation, the subsidiaries have not yet drafted a go back to work strategy. 


\section{CCenter for Promoting Education and Research (CPER) USA}

WWW.cpernet.org

Hygiene remains the main concern of people returning to work (Franklin,2020). Many companies must decide which employees could continue working from home and which should return to the office, allowing third parties to access the worksite, testing employees, developing social-distancing protocols at the workplace, and allowing traveling. Ad hoc approaches contribute to better e-working utilization. Nor do they fully realize the attraction and retention, engagement, productivity, collaboration, innovation, costs decrease, better Work-life-balance and other benefits, avoid different the risks such as technostress (Molino et al., 2020). Informality can lead to security risks, the conflict between e-employees and cubicles employees, abuses, and others.

The most implementation factors are those that allow employees to be self-supporting and effective/ productive no matter where the work is finished. As long as they have an effective technology platform, a clear understanding of their work duties, related skills and to be connected with the team and colleagues e-workers can valuable contribution to future sustainability. The choice of how, where, and when to work mostly lies in the hands of employers and employees, such trust or freedom is the key to successfully implementing of eworking policy.

\section{The Future of e-working}

According to Volini et al. (2020), leaders have the opportunity to design the future of work by founding it on the lessons and practices their organizations experienced during the crisis. The authors further conclude that during the COVID-19 pandemic, organizations practiced a burst of acceleration, fast-forwarding into the future of work in ways that stress-tested their ability to blend people and technology in the most dynamic business environment that many of us have ever seen. In a post-COVID-19 world, purpose, potential, perspective, and possibility are no longer future-focused aspirations, but the reality of the here and now.

Hayter (2020) highlights that "the future of work is not pre-determined; it is up to us to shape it". However, after COVID-19, the future has arrived sooner than expected. According to Beňo and Ferenčíková (2019), e-working will continue to increase in popularity as it is a triple win option for business, society, and our planet. The authors are seeing the beginnings of a massive shift in the definition of where work is done the "office" may just be wherever an employee has an Internet connection.

When the restrictions lift, the question remains whether this "business us unusual" will become "the new normal" (Volini et al., 2020). E-working may become an integral part after the post-COVID-19 period. Events, seminars, workshops, and fairs will go digital, using e.g. telepresence robotics to create real-life inclusive experiences. Beno (2018c) anticipates that his study will stimulate interest in the utilization of the robot by remote workers, because mobility has come to telepresence, and such development is opening up a wide range of uses for businesses.

Parungao (2020) presented three common predictions as follows: 1) remote work is here to stay; 2) technology will continue to play a significant role; 3) the proportion of work from home policies will strengthen. A more virtual workplace will mean further changes in operations. According to Vienne (2020), winning organizations will be those that integrate and master digital work, community, and collaboration. To succeed, companies need to begin planning now for five key shifts: full digital transformation supported by a truly virtual workforce; focus on outputs versus face time; respect for work-life blend; stronger communications; and increased trust, transparency, and empathy.

Successful contemporary remote companies have wellestablished processes that continually ensure that people are socializing and do not feel isolated (Berger, 2020). Kretchmer (2020) summarised work and workplace changes as follows: augmented reality workstations; rebuilt socially-distanced office; hand sanitizers, the change of cubicle density; more signs; contactless technology; fresh air (i.e. improved ventilation); co-working; new greetings avoiding shaking hands.

\section{Discussion}

Millions of people around the world have been working remotely due to the coronavirus pandemic and now, experts are asking whether this "business as unusual" could become "business as usual" at least for the people whose jobs do not require them to be tied to a particular location (Hayter, 2020). Zahidi (2020) stresses that "the future of work is here; the COVID-19 crisis calls for a fundamental reset of labor markets."

The outbreak of COVID-19 fundamentally raises questions on the ways of working, travel restrictions, the size of meetings, social contacts, and/or the self-isolation of workers after returning from affected regions. The coronavirus has created a sudden and acute need to implement e-working, to increase digitalization, to invest in new technology, to allow more flexibility (and not only at work), to ensure better virtual meetings, and hold discussions on business ethics because the demand for e-working will increase in the long run even after the end of this pandemic.

Will COVID-19 change the way we work? Will cubicles go the way of the Tasmanian Tiger in the postCOVID-19 crisis? Research of the authors indicates that coronavirus is the accelerator for organizational transformation. Some firms want employees to head back to the cubicles as soon as they can (still missing return to work strategy), others are going to encourage e-working arrangements. Most significantly, it will change everyone's priorities and values when it comes to work and personal lives. These advances will only be made if companies can implement labor policy comprehensively, especially in the post-pandemic period. 


\section{(C) Center for Promoting Education and Research (CPER) USA}

WWW.cpernet.org

There are still work activities and tasks that are best suited for personal interaction, and some employees simply prefer this. It will be disappointing if employers and managers do not continue to change the workplace once this crisis is over. COVID-19 has sparked the largest e-working experiment, has accelerated the future of work and will have an impact on the way we regard work in the coming years. The worst thing companies can do is to ignore what they learned about their workforce and their habits during the pandemic.

\section{Study Limitations}

Firstly, data collection took place utilizing e-mail questionnaires because of distance, financial aspects, and COVID-19. There is no guarantee that the researchers drew all possible information from the participants that could be used in the analysis of the data and results. However, the quality of the data depends upon the quality of the questions asked. Secondly, the sample does not reflect the population by sectoral structure. Lastly, the researchers have no way of ascertaining whether the respondents replied honestly or not. It should be stated that results from this study do not necessarily reflect how workers used to get to work will evolve in the post-pandemic period.

\section{Conclusions}

The authors' survey reflects the way the business world and its workers have responded to unprecedented workplace challenges as these employees deal with the spread of COVID-19.

The COVID-19 shock affected both the demand and supply sides of the economy (Marikawa, 2019). With COVID19 changing everything we know, old-fashioned managers with old prevailing norms, e.g. presenteeism, face-time culture, ad hoc hallway communications, excessive meetings, and attachment to inefficient technology have become obsolete. Coronavirus is not just a virus, it is a business, cultural, and societal hurricane. The use of remote working increased during the pandemic and is expected to maintain high levels of application even after the emergency (Molino et al., 2020).

In the presented survey, workers indicate a preference for smart casual dress code instead of business up top, party down below. Furthermore, for the majority of respondents, the blurred lines between personal and work life cause a high degree of distraction, as do reading social media and reading and checking the news. Workers and workplaces seem to have made their moves towards e-working for the future swiftly; more than half the workers feel they are more productive at home than in the office. More than one-third of respondents want to extend the working from home period to at least 1-2 years, and $28.57 \%$ want to continue with hybrid e-working. As the data show, the respondents still fear that it is not yet safe to return to their previous way of life. Interestingly, the subsidiaries have not yet drafted a go back to work strategy. Employers, therefore, need to continue using modern digital tools to keep in touch with employees in and out of the office. Overall, these data provide strong evidence of the benefits of e-working and act as recommendations for the future.

To conclude, digital communication and e-working are the new norms, which have to be planned carefully before implementation, taking into account the nature of the business, its global requirements, employees' requirements, as well as relevant considerations for the country concerned. Some organizations are ahead of the game, which for the moment gives them a competitive advantage for now, and perhaps for the future as well. For those behind the game, investment, organizational, social and workplace changes will be required.

As workplaces and society adopt more flexible work arrangements, it is undeniable that e-working is here to stay, as is shown in Figure 1 (Beno, 2020b).

\section{Figure 1. Out-of-Office Model}
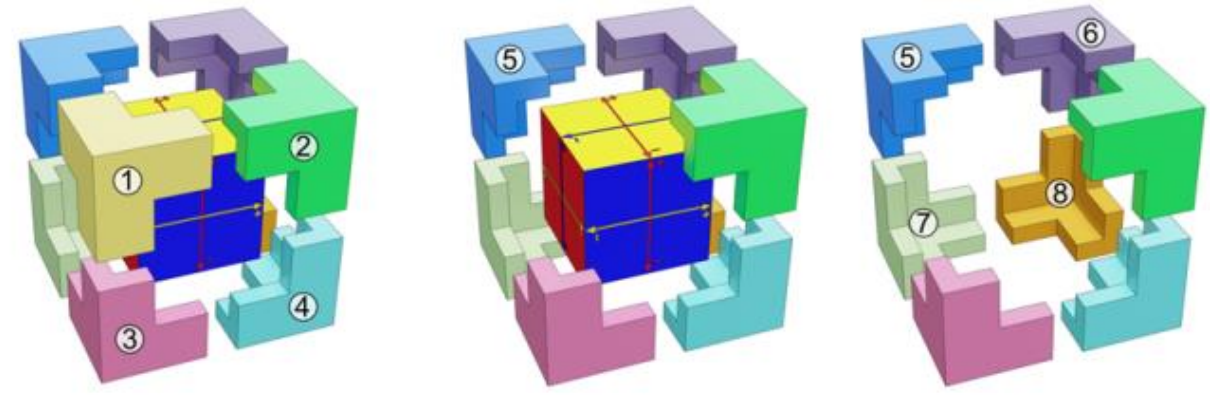

Our model is intended to help managers, employers, and countries to obtain a better understanding of future eworking. It will be useful to everyone by describing the trends, factors, and barriers, and it is organized in a way that will help everyone understand how e-working can develop (Beno, 2020b). A flexible workplace is one in which employees and employers (managers) collaborate to use a model to promote eworking, well-being, and the sustainability of the workplace by considering this Out-of-Office Model. Working models will quickly shift from futuristic ideas to standard practice. 


\section{(C) Center for Promoting Education and Research (CPER) USA}

WWW.cpernet.org

Due to the COVID-19 outbreak, the model will hesitated to implement this kind of work or were not fully become the Future for Office Workers and e-organizations; an persuaded of its positive features. E-working has become arrangement that best fits the company culture. Finding the relevant and a must in 2020 faster than in the previous 20 right e-working model boils down to organizational business years. This creates unprecedented opportunities for further needs, choosing what works best by asking employees what they want and by responding to their needs (Beno, 2020b).

As already mentioned, with the coronavirus crisis, many companies and institutions have needed to shift to eworking and home offices suddenly and unexpectedly. It has become the necessary solution, even for those who earlier research in this area, both in qualitative and quantitative terms.

\section{Acknowledgment}

The paper has been written with the support of the H2020 project with the acronym Fair Future and the title "Appreciating Intercultural Relations: A Policy Toolkit for the Promotion at the Labour Market" (1308).

\section{References}

Agarwal, P. (2018): How To Create A Positive Workplace Culture. Retrieved from:

https://www.forbes.com/sites/pragyaagarwaleurope/2018/08/29/how-to-create-a-positive-work-placeculture/\#360870242727.

Battiston, D., Blanes, J., Vidal, I. \& Kirchmaier, T. (2017). Is Distance Dead? Face-to-Face Communication and Productivity in Teams. CEPR Discussion Paper, 11924, 60.

Belzenegui-Eraso, A. \& Erro-Garcés, A. (2020). Teleworking in the Context of the Covid-19 Crisis. Sustainability, 12, 9, 3662.

Beno, M. (2018a). Transformation of Human Labour from Stone Age to Information Age. Yonas et al. (ed.), Springer, 10995, 205-216.

Beno, M. (2018b). Working In The Virtual World - An Approach To The Home Office Business Model Analysis, in AD Alta, $8,1,25-36$.

Beno, M. (2018c). Work Flexibility, Telepresence in the Office for Remote Workers: A Case Study from Austria. Lecture Notes in Computer Science, Springer, 11248, 19-31.

Beno, M. (2020a). Mobile-Teleworking - Its Effects on Work/Life Balance, a Case Study from Austria. In: Silhavy R. (eds) Artificial Intelligence and Bioinspired Computational Methods. CSOC 2020. Advances in Intelligent Systems and Computing, Springer, 1225, 161-171.

Beno, M. (2020b). Out-of-Office Model - the Eight Factors and Barriers Controlling the Future of E-Working. ACTA UNIVERSITATIS DANUBIUS, 16, 4, 150-163.

Beňo, M. \& Ferenčíková, S. (2019). The Future of Work is E-Work. 14th IWKM 2019, 7 - 8 November 2019, Bratislava Trenčín, Slovakia, 6-20.

Berger, R. (2020). Digital Workplace in the Era of Covid-19. Retrieved from: https://www.rolandberger.com/fr/Point-ofView/Digital-workplace-in-the-era-of-Covid-19.html.

Berto, L. (2016). SANT’AGOSTINO NELLO STUDIO DI VITTORE CARPACCIO. Retrieved from: https://www.ilcaffeartisticodilo.it/santagostino-nello-studio-di-vittore-carpaccio/.

Bischoff, B. \& Lapidge, M. (1994). Biblical Commentaries from the Canterbury School of Theodore and Hadrian. New York, USA: Cambridge University Press.

Bloom, N., Liang, J., Roberts, J. \& Ying, Z. J. (2015). Does Working from Home Work? Evidence from a Chinese Experiment. Quarterly Journal of Economics, 130, 1, 165-218.

Bodley, J. H. (1994). Cultural Anthropology: tribes, states, and the global system. USA: Mayfield Publishing CO.

Conway, E. (2020). Coronavirus can trigger a new industrial revolution. Retrieved frin: https://www.thetimes.co.uk/article/coronavirus-has-a-silver-lining-cz8wpc6xj.

Dávideková, M. \& Hvorecký, J. (2016). Collaboration Tools for Virtual Teams in Terms of the SECI Model. Advances in Intelligent Systems and Computing, Springer, 544, 25-36.

Dutcher, E.G. (2012). The Effects of Telecommuting on Productivity: An Experimental Examination. The Role of Dull and Creative Tasks. Journal of Economic Behavior \& Organization, 84, 1, 355-363.

Duxbury, L. \& Lanctot, A. (2017). Carleton Study Finds People Spending a Third of Job Time on Email. Retrieved from: https://newsroom.carleton.ca/archives/2017/04/20/carleton-study-finds-people-spending-third-job-time-email/. 
eDipomat. (2016). A Brief History of Diplomacy. Retrieved from: http://www.ediplomat.com/nd/history.htm.

Eurostat. (2020). How usual is it to work from home? Retrieved from: https://ec.europa.eu/eurostat/web/products-eurostatnews/-/DDN-20200206-1.

Fox, J., Murray, C. \& Warm, A. (2003). Conducting research using web-based questionnaires: practical, methodological, and ethical considerations. Int. J. Social Research Methodology, 6, 2, 167-180.

Franklin, N. 2020. Hygiene remains concern of people returning to work. Retrieved from: https://workplaceinsight.net/hygieneremains-main-concern-of-people-returning-to-work/.

Groysberg, B., Lee, J., Price, J. \& Yo-Jud Cheng, J. (2018). The Leader's Guide to Corporate Culture. Retrieved from: https://hbr.org/2018/01/the-culture-factor.

Hayter, S. (2020). 'Business as unusual': How COVID-19 could change the future of work. Retrieved from: https://news.un.org/en/story/2020/05/1064802.

ICPAS. (2017). 6 Ways to Calm Your First Day Jitters. Retrieved from: https://www.icpas.org/information/copydesk/insight/article/digital-exclusive/6-ways-to-calm-your-first-day-jitters.

ILO. (2020). Safe return to Work, Guide for employers on COVID-19 prevention. Retrieved from: https://www.ilo.org/wcmsp5/groups/public/---ed_dialogue/---act_emp/documents/publication/wcms_744033.pdf.

Kretchmer, H. (2020). COVID-19: Is this what the office of the future will look like? Retrieved from: https://www.weforum.org/agenda/2020/04/covid19-coronavirus-change-office-work-homeworking-remote-design/.

Kucharski, A. (2017): Social distancing is here to stay, and it's going to change our lives. Retrieved from: https://newsroom.carleton.ca/archives/2017/04/20/carleton-study-finds-people-spending-third-job-time-email/ .

Mark, G., Gudith, D. \& Klocke, U. (2008). The Cost of Interrupted Work: More Speed and Stress. ACM, CHI '08: Proceedings of the SIGCHI Conference on Human Factors in Computing System, 107-110.

Mastromattei, D. (2017). Sant'Agostino nello studio di Sandro Botticelli: analisi completa delle opera. Retrieved from: https://www.arteworld.it/santo-agostino-nello-studio-botticelli-analisi/.

Maxis-gbn. (n.d.): Workplace culture: helping or hurting your business? Retrieved from: https://maxis-gbn.com/MaxisGBN/files/d2/d263409c-79b3-4d31-ade6-6ce0ff3f02e6.pdf.

Michaels, E., Handfield-Jones, H. \& Axelrod, B. (2001). The War of Talent. USA: Harvard Business School Press, Boston.

Molino, M., Ingusci, E., Sigore, F., Manuti, A., Giancaspro, M. L., Russo, V., Zito, M. \& Cortese, G. C. (2020). Wellbeing Costs of Technology Use during Covid-19 Remote Working: An Investigation Using the Italian Translation of the Technostress Creators Scale. Sustainability, 12, 15, 5911.

Morikawa, M. (2020). COVID-19, teleworking, and productivity. Retrieved from: https://voxeu.org/article/covid-19teleworking-and-productivity.

OWLLabs. (2019): State of Remore Work 2019. Retrieved from: https://www.owllabs.com/hubfs/Owl\%20Labs\%202019\%20State\%20of\%20Remote\%20Work\%20Report\%20PDF.pdf .

Park, R. (1924). The Concept of Social Distance As Applied to the Study of Racial Attitudes and Racial Relations. Journal of Applied Sociology, 8, 339-344.

Parungao, A. (2020): The future of remote work after COVID-19: 3 common predictions. Retrieved from: https://www.ekoapp.com/blog/the-future-of-remote-work-after-covid-19-3-common-predictions.

Raišienè, A. G., Rapuano, V., Varkulevičiūte, K. \& Stachová, K. 820209: Working from Home-Who Is Happy? A Survey of Lithuania's Employees during the COVID-19 Quarantine Period, in Sustainability, 12, 13, 5332.

Randstad. (2019). Randstad US survey finds casual dress is (almost) always in fashion in today's workplace. Retrieved from: https://rlc.randstadusa.com/press-room/press-releases/randstad-us-survey-finds-casual-dress-is-almost-always-infashion-in-todays-workplace.

Ronander, C. (2020). What American professionals really think about remote working. Retrieved from: https://www.mentimeter.com/blog/stay-current-with-mentimeter/what-american-professionals-really-think-aboutremote-working.

Rybczynski, W. (1987). Home: A Short History of an Idea. USA: Penguin Books.

Simsek, Z. (1999). Sample surveys via electronic mail: a comprehensive perspective. RAE, 39, 1, 77-83.

Vienne, D. (2020): 5 changes to expect in the workplace after COVID-19. Retrieved from:

https://www.fastcompany.com/90496811/5-changes-to-expect-in-the-workplace-after-covid-19. 
Volini, E. et al. (2020): Returning to work in the future of work. Retrieved from: https://www2.deloitte.com/us/en/insights/focus/human-capital-trends/2020/covid-19-and-the-future-of-work.html.

WDC. (2017): e-Working in the Western Region. Retrieved from: https://www.wdc.ie/wp-content/uploads/WDC PolicyBriefing-no-7.pdf.

Wood, J. (2020): These Harvard scientists think we'll have to socially distance until 2022. Retrieved from: https://www.weforum.org/agenda/2020/04/coronavirus-social-distancing-how-long/.

Zahidi, S. (2020): The future of work is here: Why the COVID-19 crisis calls for a fundamental reset of labor markets. Retrieved from: https://www.japantimes.co.jp/opinion/2020/05/11/commentary/world-commentary/future-work-covid19-crisis-calls-fundamental-reset-labor-markets/\#.Xttdw2B7mXK . 